\title{
Quality of Operation Notes in Niger-Delta University Teaching Hospital, Southern Nigeria
}

\author{
${ }^{1}$ Olatoregun, Frank B O; Alagoa, Paingha J; Mukoro D. George \\ MBBS,FRCS,FWACS,FMCS.1 B.Med.sc, MBBS, FMCS, FICS.1 B.sc,MBBS ,DTM\&HLiverpool \\ 1.Department of Surgery, Niger-Delta University Teaching Hospital,Okolobiri, Yenagoa,Bayelsa,Nigeria
}

\begin{abstract}
:
Background: Operation notes are necessarily a vital part of good note keeping in clinical surgery as they are useful tools in patients management. They are also useful in research, audit of procedures and a sine qua non should medico-legal dispute arise. Ideally operation notes should be written by operating surgeon. This article assesses the quality of operation notes in a young teaching hospital.

Method: A total of 99 operation notes were randomly selected from a list of surgical operations between July 2008 and June 2010 of a young teaching Hospital. The operation notes were assessed for expected parameters of a standard operative note against the background of hospital templates and published protocol derived from Good surgical practice by the Royal college of surgeons, Edinburgh, 2008. Available components in the written notes were tabulated.

Result: Results showed that all the operative notes were incomplete for all parameters. Deficiencies ranged from 1\% for written operative procedure to as high as $96 \%$ for tolerance.

Other deficiencies were at rates of ;5,7,10,29, 45, 56 and 58 percentages for name of patient, name of surgeon, admission number, indications, blood loss and positioning respectively.

Conclusion. Regular audit of operation notes should be carried out and medical personnel should be properly trained concerning writing of operation notes in a legible, comprehensible and briefly way with the goal of achieving best medical practice.
\end{abstract}

Keywords: Operation notes, assessment, audit, medico-legal.

\section{Introduction:}

Operation is an act of surgery carried on a patient while an operation note is a brief written record of the surgical procedure performed on a patient. One of the cornerstones in medical practice is the legible and accurate keeping of contemporaneous patient record. According to the General Medical council (GMC),It is the doctors' duty ${ }^{1,2}$. Operation notes are useful in the management of patients post-operatively, surgical audit and research and an absolute necessity in medico-legal disputes. Lefter et al ${ }^{3}$ emphasized the medico-legal importance, stating that patients have the right to have access to their medical records subject to certain conditions s. $^{3}$.

Teaching or training health facilities still remain the place for proper acquisition of skills in writing standard operation notes. The consultant surgeon who performs an operation should write the operation notes; however, Surgeons- in training who assist may be allowed but supervised by consultant surgeon in charge. The consultant must make sure that the trainees are capable of writing good and acceptable operation notes. There are characteristics of a good operative note, such as legibility, brevity and comprehensibility with internationally recognized abbreviations where necessary. Illegible operation notes often weaken doctors defence ${ }^{4 \& 5}$

In the absence of a standard printed template with components, an operation notes can be modified to include all necessary information. This study therefore audited operation notes written in a young teaching hospital.

\section{Materials and Method:}

This is was a retrospective study of 99 operation notes randomly selected from operations carried-out between July 2008 and June 2010 .They were randomly selected by blind ballot technique.

The Operation notes were evaluated critically for the following the bio-data of patient, name, age , sex, operating personnel names, surgeon, assistant surgeon, scrub nurse, date of the operation ,duration of operation, pre-operative and post-operative diagnosis, indications, surgical findings ,name and details of surgical procedure, position of patient during surgery, skin preparation and solutions used, sutures used and suturing patterns, wound closure, blood loss, drains ,implants, tolerance of procedure and complication, and postoperative order. 
The assessed components were drawn from three templates used in the hospital as well as a publication of the Royal college of Surgeons audit. The presence of each of the components in the operation note was assigned a count of one while incomplete, absent or wrong entry was assigned zero count.

Parameters was tabulated and chart was constructed using Microsoft Excel for easy comparism.

\section{Results:}

A total of 99 operative notes were randomly selected and audited. Sixty-three of them were written by residents, ten by consultant surgeons while twenty-six had no author name. Forty-eight were in General Surgery, 23 Orthopedics, 12 Urology, 9 Paediatric Surgery, 4 Cardiothoracic and 3 were Burns and plastics.

\section{Chart 1: Operation note by Surgical specialties}

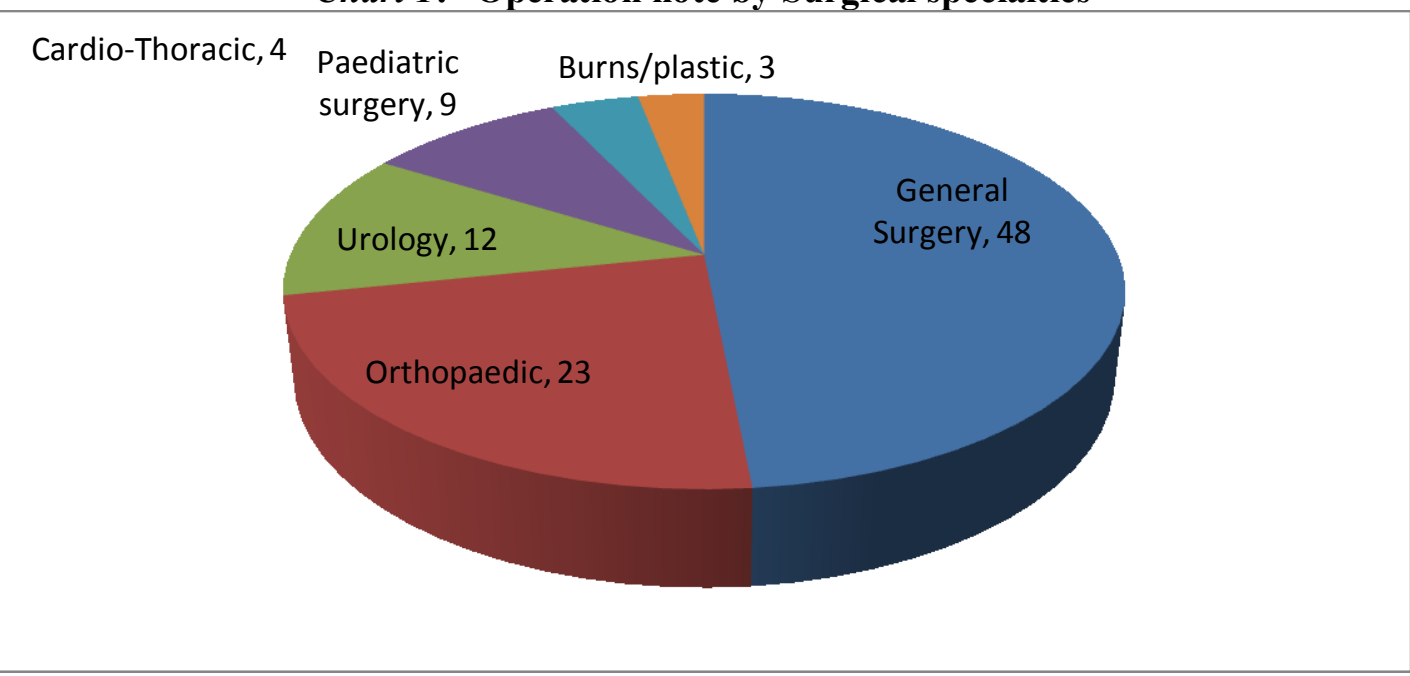

Table of 1: Identification in Operation notes

\begin{tabular}{|l|l|l|}
\hline Components of Post operative note & Number of note present & Percentage \% \\
\hline Total notes evaluated & 99 & 100 \\
\hline Admission number & 90 & 91 \\
\hline Patient name & 95 & 96 \\
\hline Patient sex & 77 & 78 \\
\hline Patient age & 63 & 64 \\
\hline Personnel Surgeon & 93 & 94 \\
\hline Personnel (assistant surgeon) & 90 & 91 \\
\hline Personnel (anaesthetist) & 71 & 72 \\
\hline Personnel (scrub nurse) & 44 & 44 \\
\hline
\end{tabular}

Table 2: components of the operation note

\begin{tabular}{|l|l|l|}
\hline $\begin{array}{l}\text { Surgical component } \\
\text { Assessed }\end{array}$ & $\begin{array}{l}\text { Number of operative note with assessed } \\
\text { components }\end{array}$ & Percentage of operative notes (\%) \\
\hline Total note used & 99 & 100 \\
\hline Pre-operative diagnosis & 71 & 72 \\
\hline indications & 54 & 54 \\
\hline Post-operative diagnosis & 65 & 66 \\
\hline Operative procedure & 98 & 99 \\
\hline Position & 41 & 41 \\
\hline Skin preparation & 2 & 2 \\
\hline Surgical Approach & 80 & 81 \\
\hline Blood loss & 43 & 43 \\
\hline Biopsy & 53 & 54 \\
\hline Drain(s)/implants & 51 & 52 \\
\hline Operative finding & 92 & 93 \\
\hline Procedure tolerance or complication & 4 & 4 \\
\hline Post-operative order & 89 & 90 \\
\hline
\end{tabular}

The second table showed that parameters that were written in the notes including those with nil or slash(-) at sites of template where such component was necessary. Few entries were less than $50 \%$. 
Table 3: Other expected operative note parameters.

\begin{tabular}{|l|l|l|}
\hline Parameters & YES & No \\
\hline Total notes assessed & 99 & 0 \\
\hline International Abbreviation & 60 & 28 \\
\hline Legibility & 94 & 5 \\
\hline Date & 71 & 28 \\
\hline Writer's signature & 67 & 32 \\
\hline Writer's name & 66 & 33 \\
\hline Fully complete & 0 & 99 \\
\hline
\end{tabular}

The third table showed that most authors wrote legibly but had left out important parameters such as date, authors name and signature. These deficiencies occurred in least a quarter of them. Furthermore, the brevity of write-up depends partly on the use of International recognized abbreviations. Sixty-two percent of notes complied using international recognized abbreviations such as IV, tabs.Non-international recognized abbreviations such as \# were used in $12 \%$ of operation notes. All surgical operative note did not meet all the criteria.

\section{Discussion}

The primary purpose of medical records is to support patient care. Improving the quality of operation notes may raise both patient outcomes and doctors' performance ${ }^{6,7}$. Well-completed, readily accessible records are the foundation of medical audit. The value of properly written operation notes in mortality and morbidity audit cannot be over-emphasized.

Our study revealed that all the operative notes were deficient for one entry or other. The extent of the problem was revealed in the results table $[1,2,3]$. Despite the fact that some operative notes were written by specialist, results showed that the problem was rampant. Our results were consistent with other articles reporting that operation notes were deficient for several entries when compared with expected standards ${ }^{1.8,9}$.

The importance and implications of each of the components cannot be undermined, such as solutions used for skin preparation. Reports had revealed adverse reaction to antiseptic solution ${ }^{10 \& 11}$.

In present day medical practice, patient awareness and enlightenment have increased toward legal litigations for suspicious practices ${ }^{4,8,9,12}$, therefore several authors had demonstrated the need for vigilance in record keeping.

In the USA, the Joint Commission on Accreditation of Hospitals evaluates the quality of medical records when assessing whether a hospital should be accredited. ${ }^{13}$ An operative note is part of medical record of a patient therefore must be in standard form to influence positive outcome.

Nevertheless, perceived reasons behind these omissions could be tiredness after a long surgery, many bookings, lack of adequate knowledge, lack of training, absence of personal or specialty audit and lack of patience. whatever, the excuses for inadequacies, good medical practice demands a standard written operation note.

Conscious effort must be made to write all necessary details required without abbreviations. If there must be any, it must be internationally recognized abbreviations ${ }^{14}$, as such contributes to writing brevity.

Internationally recognized names of procedure such as Hartman's procedure, Heineke-Miculicz, Finney's pyloroplasty and for classical approaches such as Kocher's, Gridiron, Rutherford, and Morrison also contribute to brevity of operation notes.

There are studies showing methods that could improve quality of operative notes which include Aidememoir $^{1 \& 15,16}$, word processor ${ }^{14,17 \& 18}$ and computerization of records ${ }^{1}$ in the theatre.

Other area for exploitations includes printed proforma with tick boxes. Proformas has been reported to improve medical recording ${ }^{19}$, while tick boxes prevent non-legible writing ${ }^{20}$, aids retrieval of information and improves patient's care ${ }^{21}$.

\section{Conclusion:}

Regular audit of operating note should be carried out and proper training of medical personnel in writing operation notes legibly, briefly comprehensibly with mind-set toward achieving standard medical practice.

\section{Reference}

[1]. Shah S, Dangol B, Kumari S, Guragain R P. An audit of Operative note at TUTH. Nepalese Journal of Ent, head and neck surgery , Vol 2,No2,issue 2 July-Dec 2011

[2]. General Medical council, Good Medical Practice, GMC 2011

[3]. Lefter LP,Walter SR, Dewhurst F and Turner RWL.An Audit of operative notes:facts and ways to improve.ANZ J.Surg.2008;78:800-2

[4]. Bastia BK.Litigation suits in Otorhinolaryngology, areas of concern, Indian Journal of otolaryngology and head and neck surgery 2006:58;1;370-3. 
[5]. Mathew J,Baylis C,Saklani AP ,AL-Dabbagh AR, Quality of operative note in a district general Hospital:a time for change? internet J.Surg $2003 ; 5: 116-9$.

[6]. Swansea Physician's Audit Group. Audit of the quality of medical records in a district general medicine unit. J R Coll Physicians Lond 1983; 17: 208-212.

[7]. Mann R, Williams J. Standards in medical record keeping. Clin Med 2003;3: 329-332.

[8]. I. Chamisa, B. M. W. Zulu, Setting the records straight - a prospective audit of the quality of case notes in a surgical department SAJS Vol 45, No. 3, august 2007

[9]. A. Ogbemudia, L.W. Osemwegie; Quality of Operation notes following Orthopaedic Procedures in A tertiary Centre:Aneed for Reorientation. Ann Biomed Sci Vol10,No2,June 2011.

[10]. Goon, et al-Allergic contact dermatitis from chlorhexidine ,Dermatitis 2004 March;15(1)45-7.

[11]. Lasthoin B et al,Contact dermatiis from chlorhexidine,Contact dermatites 1985 Oct :13(5)307-9.

[12]. Saunders M. Problems with notes. Journal of Medical Defence 1988; 297: 1256-1259.

[13]. Berwick C, Winickoff DE. The truth about doctors handwriting: a prospective study. BMJ 1996; 313: 1657-1658.

[14]. A Bhayah, F.o.Agada,S.Gunasekaran,P.Jassar.The quality of operative note taking:An audit using the Royal colledge of Surgeons Guideline as gold standard Int J.Clinical Practice.2007:61(4):677-9.

[15]. O'Bichere A,Sellu D.The quality of operation notes:can simple word processors help?Ann,R coll Surg.Engl.1997;79204-8.

[16]. Bateman ND,Carney AS,Gibbin KP.(1999) An audit of the quality of operation notes in an Otolaryngology unit.J R Coll Surg Edinb 44:94-5.

[17]. Barlow IW,Flyn NA, Briton JM(1994) The Basingstoke Orthopaedic Database:a high quality accurate information system for audit.Ann R Coll Surg Engl.76:285-7

[18]. Baigrie RJ,Dowling BL,Birch D,Dehn TC .(1994) An audit of the quality of operation notes in two district general hospitals.Are we following Royal Colledge guidelines?Ann R Coll Surg Engl 76:8-10.

[19]. Irtiza-Ali A, Houghton CM, Raghuram A, O’Driscoll BR. Medical admissions can be made easier, quicker, better by use of a preprinted medical admissions proforma. Clin Med 2001; 1:327.

[20]. Berwick C, Winickoff DE. The truth about doctors handwriting: a prospective study. BMJ 1996; 313: 1657-1658.

[21]. Campbell H, Hotchkiss R, Bradshaw N, Porteous M. Integrated care pathways. BMJ 1998; 316: 133-137. 